\title{
Effect of Clindamycin on Reproductive Function in Female Wistar Rats
}

\author{
Oyedeji K.O.*1, Okunlola O. ${ }^{1}$, Zachariah Richard ${ }^{2}$ \\ 1. Department of Physiology, College of Medicine and Health Sciences, Afe Babalola University, Ado-Ekiti, Nigeria. \\ 2. Department of Anatomy, College of Medical Sciences, Ahmadu Bello University, Zaria, Nigeria. \\ *Corresponding author's E-mail: sinaoyedeji@yahoo.com
}

Received: 17-10-2021; Revised: 21-11-2021; Accepted: 28-11-2021; Published on: 20-12-2021.

\begin{abstract}
This study was designed to investigate the effect of clindamycin on reproductive function in female Wistar rats. Fifteen female rats $(120-160 \mathrm{~g})$ were used for the estrous cycle and histopathological studies. Clindamycin $(8.57 \mathrm{mg} / \mathrm{kg})$ was administered orally on daily basis for 21 and 50 days respectively for the estrous cycle and histological studies. Estrous cycle was carried out using the technique of Marcondes et al., histologies of the ovaries and uteri were also carried out. Data were analysed using descriptive statistics and student's t-test at $p=0.05$. Treatment of rats for 21 days with clindamycin $(8.57 \mathrm{mg} / \mathrm{kg})$ produced significant $(\mathrm{p}<0.05)$ reductions in the proestrous and diestrous phases as well as significant $(p<0.05)$ increments in the estrous and metestrous phases of the estrous cycle relative to their respective controls. The histopathological study presented with no deleterious effects on the ovarian and uterine tissues in the rats. It can therefore be concluded that clindamycin probably has pro-fertility effect without deleterious effects on the ovaries and uteri at histological level in female Wistar rats.
\end{abstract}

Keywords: Clindamycin, Proestrous, Estrous, Ovaries, Rats.

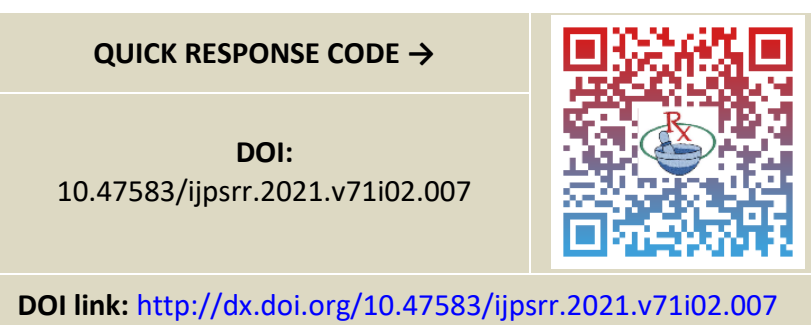

\section{INTRODUCTION}

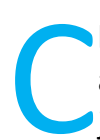

lindamycin is an antibiotic used for the treatment of a number of bacterial infections, including bone or joint infections, pelvic inflammatory disease, strep throat, pneumonia, middle ear infections, and endocarditis. It can also be used to treat acne ${ }^{1}$, and some cases of methicillin-resistant Staphylococcus aureus (MRSA) ${ }^{2}$.

The oral toxicity of clindamycin in laboratory animals has been reported ${ }^{3}$. Its biological and histopathological effects on albino rat fetuses have been reported ${ }^{4}$. Its effects on intestinal water and glucose transport in the rat ${ }^{5}$ as well as in a model of acute murine toxoplasmosis have been reported ${ }^{6}$. The effect of clindamycin given alone or with Lactobacillus delbrueckii and Streptococcus thermophilus on $7 \alpha$-dehydroxylation of bile acids in rats has also been reported ${ }^{7}$. However, due to scanty information from literature on the effect of clindamycin on reproductive parameters in female rats, this study therefore aims at investigating the effect of this antibiotic on these aforementioned parameters in female rats.

\section{MATERIALS AND METHODS}

\section{Experimental Animals}

Adult female rats weighing between $120 \mathrm{~g}-160 \mathrm{~g}$ bred in the Pre-Clinical Animal House of the College of Medicine and Health Sciences, Afe Babalola University were used. They were housed under standard laboratory conditions and had free access to feed and water; they were acclimatized for two weeks to laboratory conditions before the commencement of the experiments. All experiments were carried out in compliance with the recommendations of Afe Babalola University Ethics Committee on guiding principles on care and use of animals.

\section{Drug}

Clindamycin hydrochloride capsules (Government Pharmaceutical Organization, Thailand) were bought from Danax Pharmacy, Ibadan, Nigeria.

Clindamycin hydrochloride $(300 \mathrm{mg}$ ) was dissolved in $10 \mathrm{ml}$ of distilled water to give a concentration of $30 \mathrm{mg} / \mathrm{ml}$.

The dosage of clindamycin used in this study was in accordance with that reported by the manufacturer.

\section{Experimental Design}

\section{Study on Estrous Cycle}

Five matured female rats showing at least three regular 4 -5 day cycles were used for this study. Vaginal lavages (smears) were examined microscopically every day at a constant interval of $4.30-5.30$ p.m. for 21 days before and after treatments with the antibiotic. The smears were classified into one of the phases of the estrous cycle using the Marcondes technique ${ }^{8}$. Vaginal secretion was 
collected with a plastic pipette filled with $10 \mu \mathrm{L}$ of normal saline ( $\mathrm{NaCl} 0.9 \%)$ by inserting the tip into the rat's vagina, but not deeply. Vaginal fluid was placed on glass slide. One drop was collected with a clean tip from each rat. Unstained material was observed under a light microscope, without the use of condenser lens, with 10 and $40 \mathrm{x}$ objective lenses. Three types of cells could be recognized: round and nucleated ones are epithelial cells; irregular ones without nucleus are the cornified cells; and the little round ones are the leucocytes. The proportion (preponderance) among them was used for the determination of estrous cycle phases ${ }^{9,10}$. The duration of the estrous cycle was determined. In this study, the experimental animals also served as the control. The first 21 days served as the control days, while the last 21 days served as the treatment days. Each of the 5 rats for this estrous cycle study received $8.57 \mathrm{mg} / \mathrm{kg}$ of clindamycin.

\section{Histopathological Study}

In another set of experiment, ten matured female rats divided into two equal groups (five animals per group) received the following treatment of the antibiotic and control (orally) per day for fifty days as follows:

Group I rats received $0.5 \mathrm{ml} / 100 \mathrm{~g}$ of distilled water as the control group.

Group II rats received $8.57 \mathrm{mg} / \mathrm{kg}$ of clindamycin.

On the 51st day, all the rats were sacrificed by an overdose of chloroform. The ovaries and uteri were dissected out, cleaned of fat and immediately fixed in Bouin's fluid.

\section{Histological preparation of tissues}

After weighing the ovaries and uteri, they were immediately fixed in Bouin's fluid for 12 hours and the Bouin's fixative was washed from the samples with $70 \%$ alcohol. The tissues were then cut in slabs of about $0.5 \mathrm{~cm}$ transversely and the tissues were dehydrated by passing through different grades of alcohol: $70 \%$ alcohol for 2 hours, $100 \%$ alcohol for 2 hours, and finally $100 \%$ alcohol for 2 hours. The tissues were then cleared to remove the alcohol, the clearing was done for 6 hours using xylene. The tissues were then infiltrated in molten paraffin wax for 2 hours in an oven at $57^{\circ} \mathrm{C}$, thereafter the tissues were embedded. Serial sections were cut using rotary microtone at 5 microns $(5 \mu \mathrm{m})$. The satisfactory ribbons were picked up from a water bath $\left(50-55^{\circ} \mathrm{C}\right)$ with microscope slides that had been coated on one slide with egg albumin as an adhesive and the slides were dried in an oven. Each section was deparaffinized in xylene for 1 minute before immersed in absolute alcohol for 1 minute and later in descending grades of alcohols for about 30 seconds each to hydrate it. The slides were then rinsed in water and immersed in alcoholic solutions of hematoxylin for about 18 minutes. The slides were rinsed in water, and then differentiated in $1 \%$ acid alcohol and then put inside a running tap water to blue and then counterstained in alcoholic eosin for 30 seconds and rinsed in water for a few seconds, before being immersed in $70 \%, 90 \%$ and twice in absolute alcohol for 30 seconds each to dehydrate the preparations. The preparations were cleared of alcohol by dripping them in xylene for I minute. Each slide was then cleaned, blotted and mounted with DPX and cover slip, and examined under the microscope. Photomicrographs were taken at $x 40$ and x100 magnifications.

\section{Statistical Analysis}

The mean and standard error of mean (S.E.M.) were calculated for all values. Comparison between the control and the treated group was done using student's t-test. Differences were considered statistically significant at $\mathrm{p}<0.05$.

\section{RESULTS}

Treatment of rats for 21 days with clindamycin $(8.57$ $\mathrm{mg} / \mathrm{kg}$ ) produced significant $(p<0.05)$ reductions in the proestrous and diestrous phases as well as significant $(p<0.05)$ increments in the estrous and metestrous phases of the estrous cycle relative to their respective controls (Figure 1)

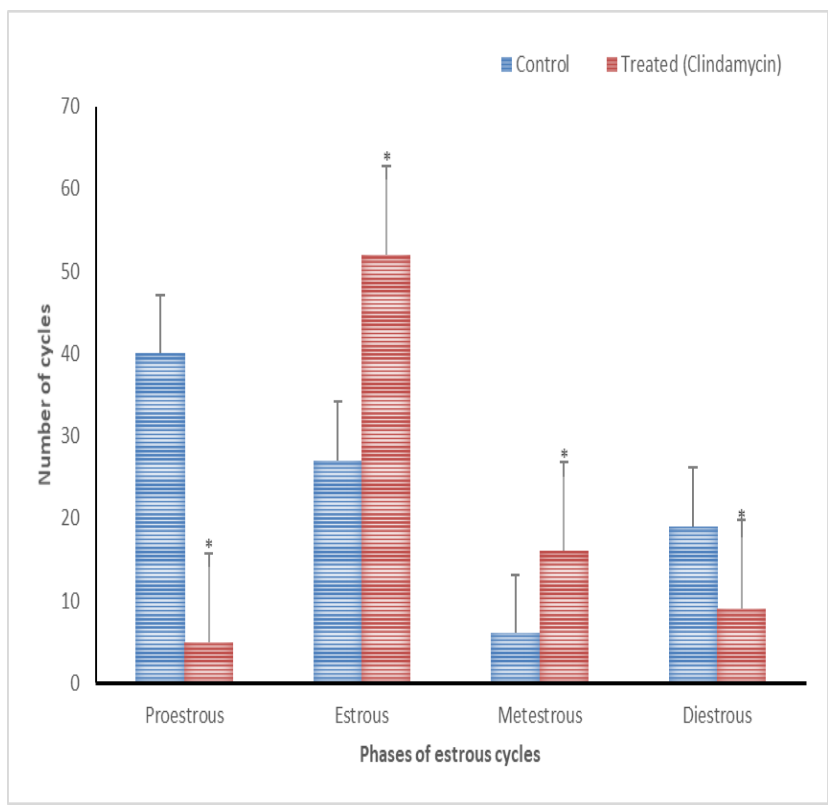

Figure 1: Effect of 21 days treatment with clindamycin on estrous cycle $(n=5, * p<0.05)$

Treatment of rats with clindamycin $(8.57 \mathrm{mg} / \mathrm{kg})$ for 50 days produced no pathological effects on the ovaries, which is similar to what was observed in the control rats (Plates 1 and 2).

Treatment of rats with clindamycin $(8.57 \mathrm{mg} / \mathrm{kg})$ for 50 days produced no pathological effects on the uteri, which is similar to what was observed in the control rats (Plates 3 and 4). 


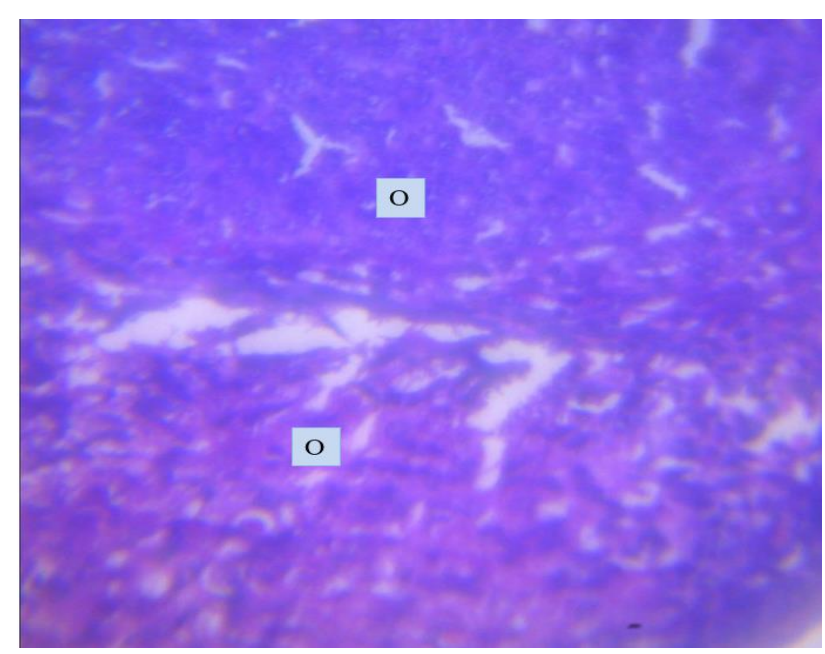

Plate 1: Effect of $0.5 \mathrm{ml} / 100 \mathrm{~g}$ distilled water (control) on the ovary at $x 400$. Photomicrograph showing a normal ovary (O) with no visible lesions seen.

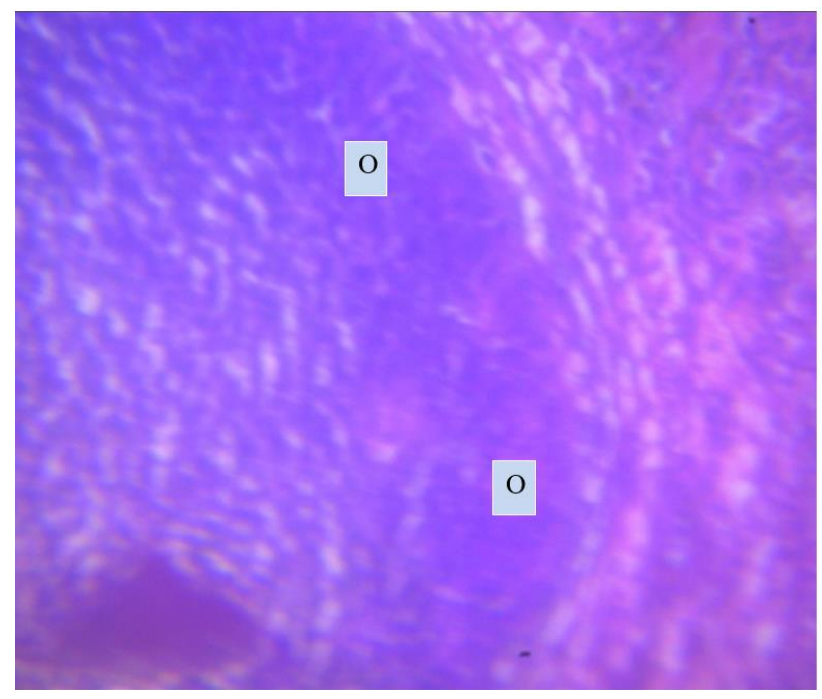

Plate 2: Effect of clindamycin $(8.57 \mathrm{mg} / \mathrm{kg})$ on the ovary at $x$ 400. Photomicrograph showing an ovary (O) with no pathologic lesions seen.

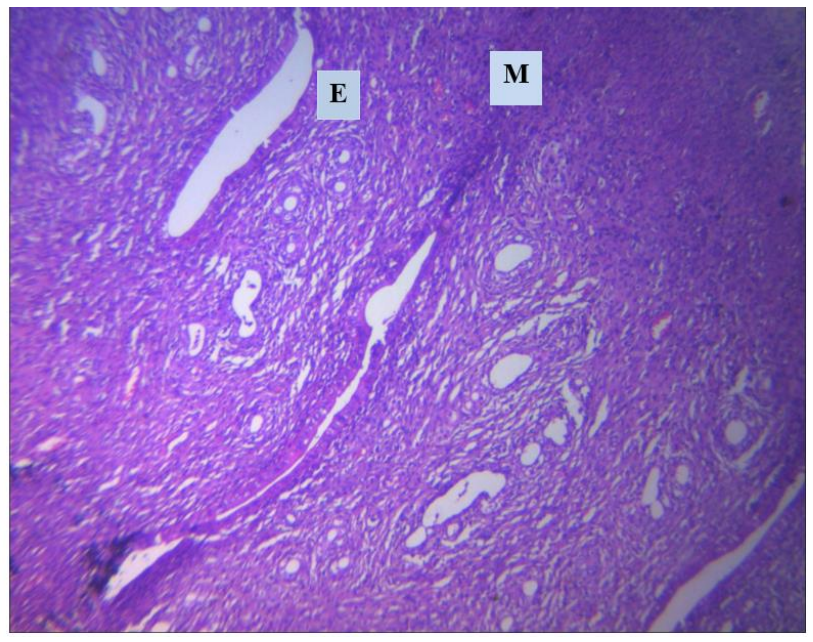

Plate 3: Effect of $0.5 \mathrm{ml} / 100 \mathrm{~g}$ distilled water (control) on the uterus at $\times 400$. Photomicrograph showing normal endometria ( $E$ ) and myometrium (M) no visible lesions seen.

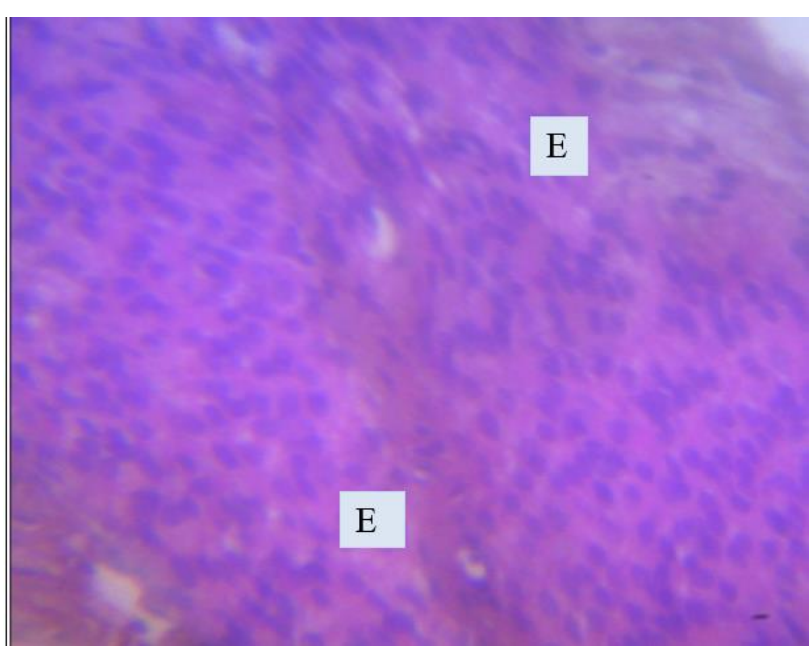

Plate 4: Effect of clindamycin $(8.57 \mathrm{mg} / \mathrm{kg})$ on the uterus at $\mathrm{x} 400$. Photomicrograph showing endometrial (E) layer with no pathologic lesions present.

\section{DISCUSSION}

The estrous cycle study revealed that clindamycin caused significant changes in the duration of different phases of the estrous cycle. Contrary report was given by ${ }^{11}$ in Portulaca oleracea extracts treated rats. This suggests that the antibiotic caused imbalances of the ovarian and extraovarian hormones, since it has been reported that imbalance in these hormones lead to irregularity in the ovarian functions and duration of the estrous cycle ${ }^{12}$.

Treatment of rats with clindamycin caused significant decrease in proestrous phase of the estrous cycle which probably indicates that the maturation of the follicles in the preovulatory phase was hastened leading to maturation of the Graafian follicles. Contrary result was reported by ${ }^{13}$ in alcohol treated rats. Treatment of rats with clindamycin caused significant increase in estrous phase of the estrous cycle which suggests the availability of matured Graafian follicles and would lead to ovulation. Similar result was reported by ${ }^{14}$ in alcohol treated rats. Also, treatment of rats with clindamycin caused significant increase in metestrous phase of the estrous cycle which probably indicates the availability of matured Graafian follicles. Similar result was given by ${ }^{15}$ in tetracycline treated rats. In addition, treatment of rats with clindamycin caused significant reduction in dietestrous phase of the estrous cycle which suggests an increase in the frequency of ovulation. Similar result was reported by 16 in amlodipine treated rats.

The ovarian photomicrographs of the clindamycin treated rats presented with no pathologic lesion which suggests the non-toxic effect of the drug on the ovaries at histological level. Similar results were reported by ${ }^{11}$ in Portulaca oleracea treated rats.

The uterine photomicrographs of the clindamycin treated rats revealed no pathologic lesion which probably indicates the non-toxic effect of the drug on the uteri at histological level. Similar results were reported by ${ }^{17}$ in Allium sativum extract treated rats. 
It can therefore be concluded that clindamycin probably has pro-fertility effect without deleterious effects on the ovaries and uteri at histological level in female Wistar rats. However, the effect of this antibiotic on human reproductive function is unknown; nevertheless, considering these findings in animal model, it is recommended that women with infertility problems could take clindamycin for infertility therapeutic purpose.

\section{REFERENCES}

1. Leyden JJ. Hidradenitis suppurativa. Berlin: Springer. 2006; p. 152. ISBN 9783540331018. Archived from the original on 8 September 2017.

2. Daum RS. Clinical practice. Skin and soft-tissue infections caused by methicillin-resistant Staphylococcus aureus. N. Engl. J. Med. 2007; 357(4): 380-390.

3. Gray JE, Weaver RN, Bollert JA, Feenstra ES. The oral toxicity of clindamycin in laboratory animals. Toxicol. and Appl. Pharmacol. 1972; 21(4): 516-531.

4. El Ghareeb AEW, Amer MA, Abdelrahman HA, AlShebany G. Biological and histopathological studies on the effect of the antibiotic clindamycin on albino rat fetuses. Asian J. Appl. Sci. 2016;4(4):18-24.

5. Giannella RA, Serumaga J, Walls D, Drake KW. Effect of clindamycin on intestinal water and glucose transport in the rat. Gastroenterol. 1981;80(5):907-913.

6. Vuković D, Djurković-Djaković $O$, Kovačević $S$, Bobić $B$, Nikolić A, Todorović V, Babić D. Effect of clindamycin in a model of acute murine toxoplasmosis. Clinic. Microbiol. and Infect. 1997;3(1):89-94.

7. Gustafsson A. Effect of clindamycin given alone or with Lactobacillus delbrueckii and Streptococcus thermophilus on $7 \alpha$-dehydroxylation of bile acids in rats. Clinic. Microbiol. and Infect. 2008;4(10):594-598.
8. Marcondes FK, Bianchi FJ, Tanno AP. Determination of the estrous cycle phases of rats: some helpful considerations. Braz. J. Bio. 2002;62(4a):609-614.

9. Long JA, Evans HM. The estrous cycle in the rat and its associated phenomena. Memo. Uni. Califor. 1922;6:1148.

10. Mandl AM. The phases of the oestrous cycle in the adult white rat. J. Exptal. Bio. 1951;28:576-584.

11. Oyedeji KO, Bolarinwa AF. Effects of extracts of Portulaca oleracea on reproductive functions in female albino rats. Afr. J. Biomed. Res. 2010;13:213-218.

12. Circosta C, Sanogo R, Occhiuto F. Effects of Calotropis proceraon estrous cycle and on estrogenic functionality in rats. Farmaco. 2001;56:373-378.

13. Oyedeji KO, Bolarinwa AF, Azeez, AA. Effect of effect of methanolic extract of Vernonia amygdalina on reproductive parameters in male rats. Asian J. Pharm. Cli Res. 2013;6(2):1-4.

14. Oyedeji KO, Bolarinwa AF, Fashina AM. Effect of alcohol consumption on hematological and reproductive parameters in female albino rats. IOSR J. Dent. Med. Sci. 2013;3(5):76-79.

15. Oyedeji KO, Bolarinwa AF, Afolabi OA. Effect of tetracycline on haematological and reproductive parameters in female albino rats. Asian J. Pharm. and Clin. Res. 2013;6(2):227-229.

16. Oyedeji KO, Abidoye AO, Alomo TO, Zachariah R. Effect of amlodipine (Calcium channel blocker) on reproductive function in female Wistar rats. J. Pharm. Sci. \& Res. 2019; $11(12): 3741-3744$.

17. Raji LO, Fayemi OE, Ameen SA, Jagun AT. The effects of aqueous extract of Allium sativ um (Garlic) on some aspects of reproduction in the female albino rats. Global Vet. 2012;8(4):414-420.

Source of Support: The author(s) received no financial support for the research, authorship, and/or publication of this article.

Conflict of Interest: The author(s) declared no potential conflicts of interest with respect to the research, authorship, and/or publication of this article. 